\title{
Innovations in pancreatic anastomosis technique during pancreatoduodenectomies
}

\author{
S. Ferencz ${ }^{1}$ - Zs. Bíró ${ }^{2} \cdot$ A. Vereczkei ${ }^{1} \cdot$ D. Kelemen ${ }^{1}$ (i) \\ Received: 16 June 2020 / Accepted: 21 July 2020 / Published online: 31 July 2020 \\ (C) The Author(s) 2020
}

\begin{abstract}
Purpose Pancreatic fistula following pancreatic resections is still a relevant complication. The present work shows the efforts of a single institute to decrease this problem.

Methods A total of 130 patients (63 men, 67 women) with a mean age of 60 (range: 23-81) years were operated on between January 2013 and March 2020. The most frequent type of pancreatic resection was a Whipple procedure with partial antrectomy. During all operations, an innovative method was used, namely a modification of the purse-string suture pancreatojejunostomy. Moreover, an early drain removal policy was applied, based on the drain amylase level on the first and subsequent postoperative days.

Results Mean postoperative hospital stay was 13 days (range: 7-75). The overall morbidity rate was $43.8 \%$; the clinically relevant (grade B/C) pancreatic fistula (CR-POPF) rate was 6.9\%. Delayed gastric emptying (DGE) was observed in $4 \%$ of the patients. The ratio of operative mortality was $0.7 \%$; the reoperation rate was $5.3 \%$. Based on the drain amylase level on the first postoperative day, two groups could be established. In the first one, the drain was removed early, on the fourth day in average (range: 2-6). In the other group, the drain was left in situ protractedly or reinserted later on.

Conclusion A single center's experience proves that the refinement of the technique can improve the results of pancreatic surgery.
\end{abstract}

Keywords Pancreatic resection $\cdot$ Purse-string suture pancreatojejunostomy Pancreatic fistula $\cdot$ Drain amylase level

\section{Introduction}

Surgical morbidity rate after pancreatic resections is still high (up to 50\%) even in specialized centers. Beside delayed gastric emptying, biliary fistula, postoperative hemorrhage, surgical site infection, and other morbidities, pancreatic fistula is the most relevant complication with a rate of $10-15 \%$ after pancreatoduodenectomies [1]. Many efforts have been done to decrease this number, like several modifications of the pancreato-enteric anastomosis, stenting of the pancreatic duct, administration of somatostatin, etc.; however, no single method has been proven to be superior, according to the reviews and meta-analyses [2]. That is why pancreatic surgeons have continuously tried to find the ideal method for decades. The present paper shows such efforts of a single institute.

\section{Kelemen}

kelemende@gmail.com

1 Department of Surgery, Clinical Center, Medical School, University of Pécs, Pécs, Hungary

2 Division of Surgery, County Hospital, Szombathely, Hungary

\section{Material and methods}

Between January 2013 and March 2020, 130 Whipple procedures (74 with partial antrectomy and 56 with preservation of the pylorus) were performed at the Department of Surgery, Clinical Center, Medical School, University of Pécs, Pécs, Hungary. Table 1 summarizes the patients' data. The gender distribution was almost equal and the mean age was 60 years. The most common disease was a pancreatic neoplasia. During the procedure - after the radical resectional phase - a very simple type end-to-side pancreatojejunostomy was created with only three stitches. After mobilization of the pancreatic stump up to 2-3 cm distally, on the antimesenteric border of the jejunal limb, an enterotomy was made with a length of $2 /$ 3 rd the diameter of the stump in order to get a tight contact after the implantation of the pancreas into the bowel lumen. Afterwards, a seromuscular 2/0 monofilament nonabsorbable purse-string suture was put in the bowel wall about 3-4 mm from the edge of the opening. The next step was to put two Ushaped fixing sutures to the cranial and caudal corner of the pancreas (order: jejunum outside-in - pancreatic cornerjejunum inside-out), as well, with $3 / 0$ monofilament 
Table 1 Patient data ( $n: 130)$

\begin{tabular}{clc} 
Gender & \multicolumn{1}{c}{ Male: 63} & Female: 67 \\
Mean age & 60 years (range: $23-81$ ) & \\
Diagnosis & Pancreatic neoplasia: 81 & \\
& Neoplasia of the papilla Vateri: 24 \\
& Distal bile duct neoplasia: 12 \\
& Chronic pancreatitis: 5 \\
& Duodenal neoplasia: 4 \\
& Cystic neoplasia: 4
\end{tabular}

absorbable suture material. Care was taken not to hurt the small vessels at the mesenteric border with the $U$ stitches (Figs. 1, 2, 3, and 4.) By knotting the U stitches, the pancreas was implanted and fixed into the bowel; then, the purse-string suture was knotted. Our first experiences with this technique were previously published $[3,4]$. Noteworthy tricks during the creation of the anastomosis were identified, namely the importance of turning the jejunal mucosa into the bowel lumen with a fine dissector Pean before tightening the purse-string stitch. Thus, the bowel serosa touched to the pancreatic surface, which is a prerequisite for the healing of the anastomosis. Avoidance of supplementary stitches is important, as the

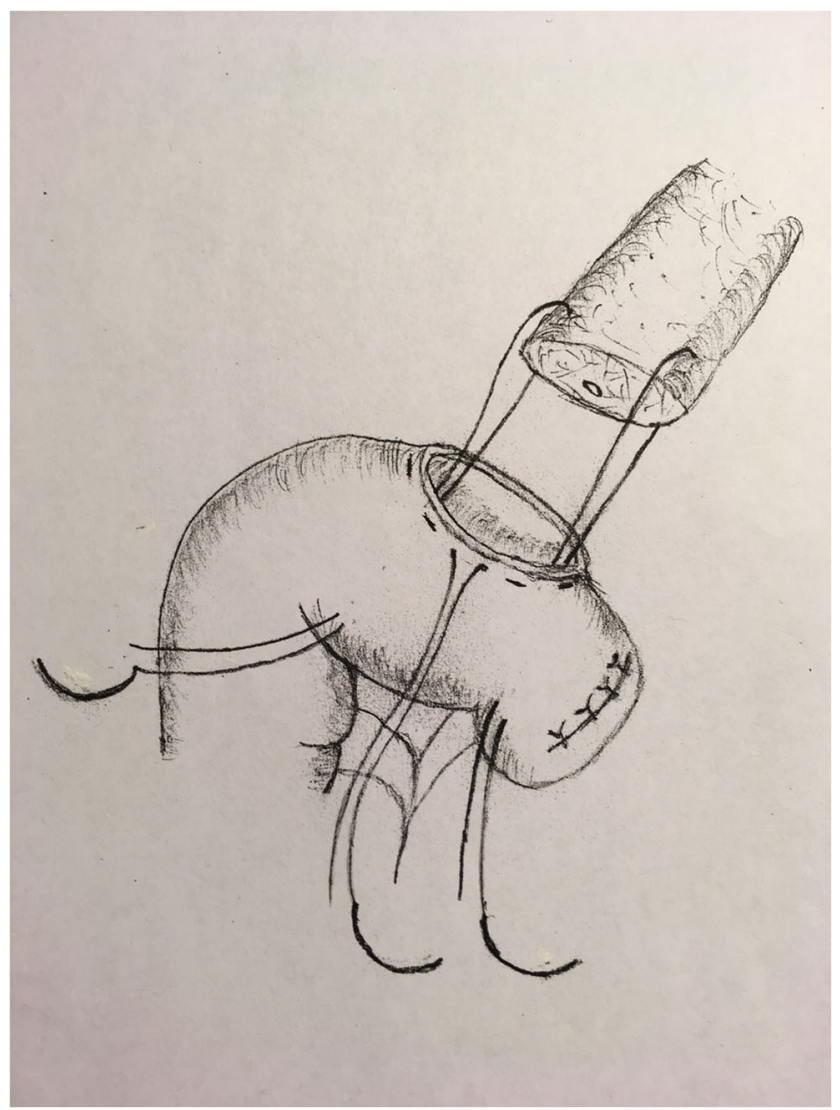

Fig. 1 Schematic drawing of the end-to-side pancreatojejunostomy, created with a single purse-string stitch and two U-shaped fixing sutures

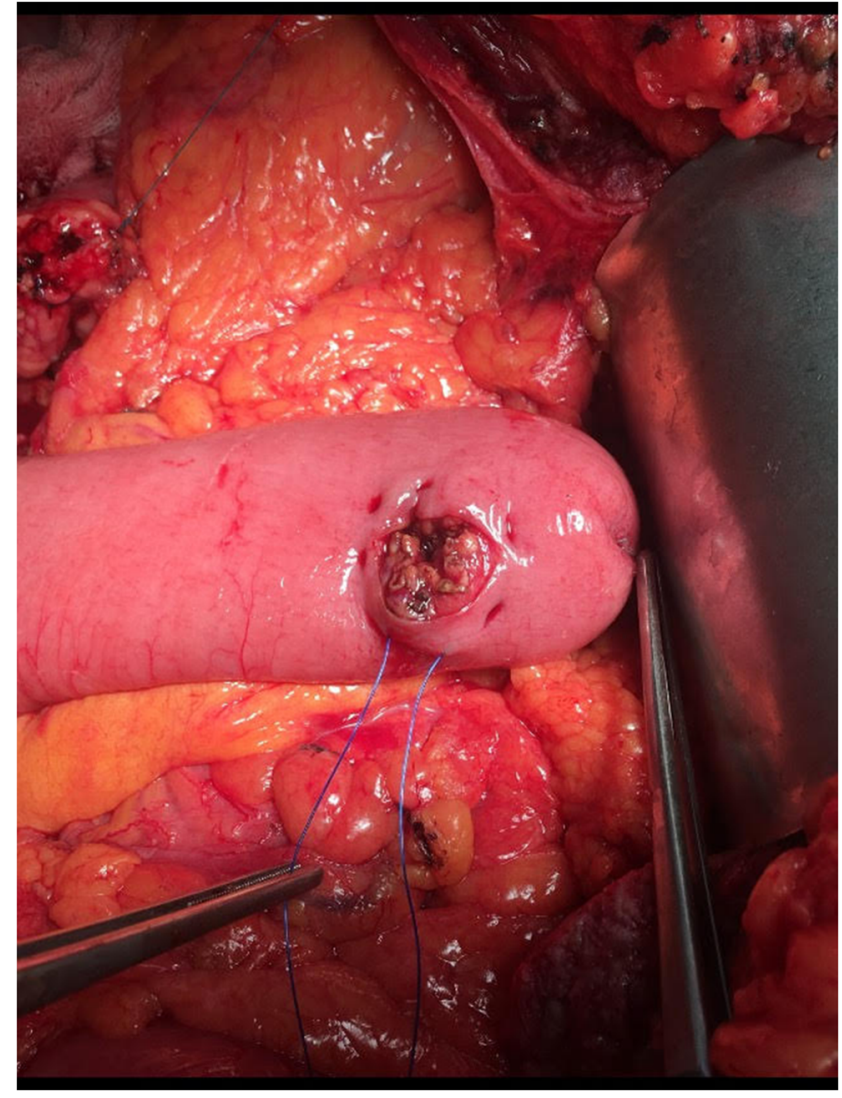

Fig. 2 A purse-string suture was put around the jejunal opening

essence lies in the application of a single suture. The tightness of the knot was gently checked with a metal probe. Moreover, the knot of the U stitches was covered with a single serosal suture. Our technique is a simple modification of the pursestring suture pancreato-enteric anastomosis, which was first published by Spivack and Wile [5], then popularized by others [6]. One soft silicon drain was positioned in front of the pancreatojejunostomy and this area was covered with the omentum in order to fix the drain and also to create a localized space for the case of pancreatic fistula. The drain was placed after the operating table was put back to the flat position. The number of cases with normal parenchymal texture (66) was almost equal to the fibrotic one (64). The order of the further anastomoses was hepaticojejunostomy (continuous suture in case of a dilated duct and interrupted stitches in case of a narrow one), then antecolic duodeno-, or gastrojejunostomy with an additional Braun anastomosis between the afferent and efferent loop. During the operation, regional lymphadenectomy was routinely performed. In the perioperative period, the enhanced recovery principles were applied, like preoperative counseling, avoidance of preoperative biliary drainage (if possible), smoking and alcohol cessation, preoperative nutrition (if it needs), chemical and mechanical thromboprophylaxis, antibioprophylaxis and skin preparation, epidural analgesia, avoidance of hypothermia and also hyperglycemia, near-zero 


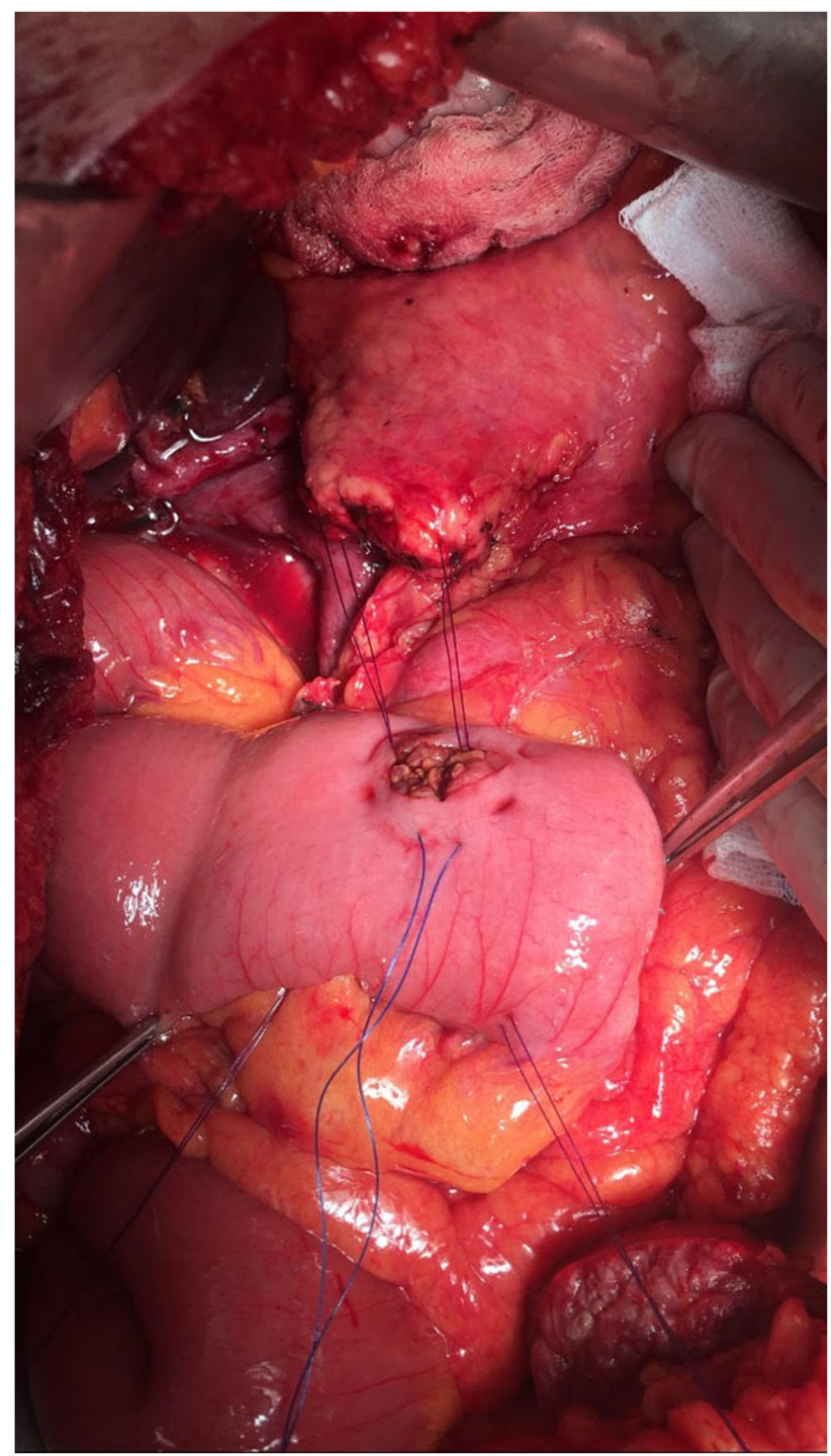

Fig. 3 Two U-shaped fixing sutures were placed

fluid balance, early perianastomotic drain removal, omitting somatostatin analogues, stimulation of bowel movement, early enteral feeding, and mobilization, etc. [7]. Drain amylase level was routinely measured on the first postoperative day and also before drain removal. Our aim was to investigate its changes in case of CR-POPF and in the lack of it. The drain management was guided by the policy of the Verona group [8]. The rate of CRPOPF and other complications was also recorded [9, 10]. Octreotide was administered for 7-10 days only in case of a manifest pancreatic fistula.

\section{Results}

Mean postoperative hospital stay (including 2-3 days in ICU) was 13 days (range: 7-75). Tables 2 and 3 . show the

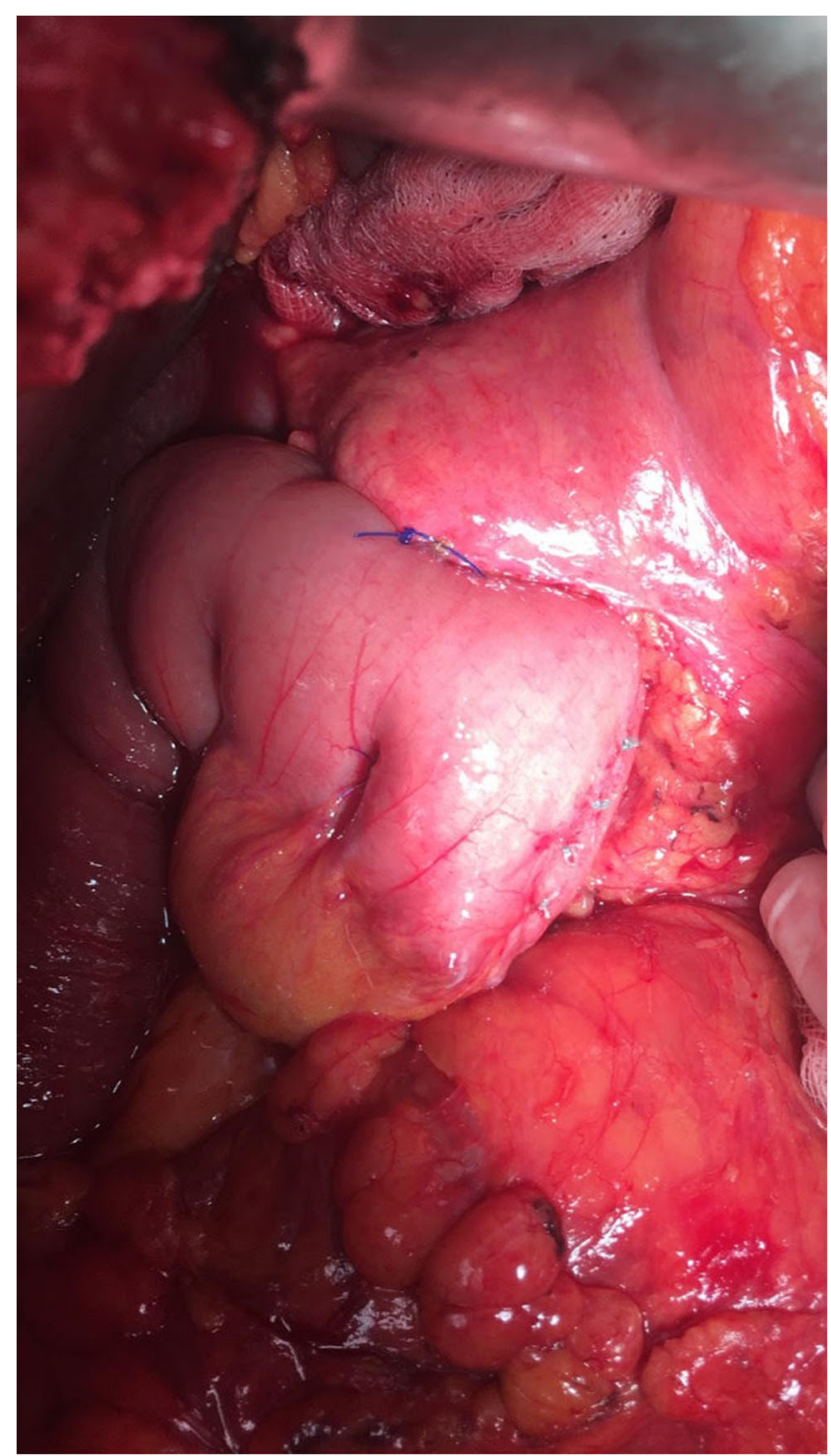

Fig. 4 The ready anastomosis after knotting of the three stitches

postoperative results. The overall morbidity rate was $43.8 \%$, the CR-POPF rate was $6.9 \%$, and DGE was in $4 \%$ of the cases (grade A). Operative mortality was $0.7 \%$ and the reoperation rate was $5.3 \%$. Data of drain amylase level on the first postoperative day was available in about $2 / 3$ rd of the cases. Using these numbers, two groups were established (group 1: no fistula, group 2: CR-POPF), presented in Table 4. In group 1, the mean amylase level of drain fluids (2137 U/1, range: 646,000) was under $5000 \mathrm{U} / 1$; however, in the group 2, these numbers were much higher $(19,550 \mathrm{U} / 1$, range: $28-63,690)$, except 9 cases in group 1 and one case of group 2, where the level was above or under the $5000 \mathrm{U} / 1$ limit, respectively. In group 1, the drain was removed on the fourth day in average (range: 2-6) and on that day the mean amylase level was 264 U/1 (range: 3-3370). In group 2, the drain was left in situ or reinserted later on. If there was no recorded data on the first postoperative day, then the time of drain removal was decided 
Table 2 Nonsurgical morbidity, reoperation, and operative mortality
Nonsurgical complications $n: 26(20 \%)$

Reoperation $n: 7(5.3 \%)$
Pneumonia, respiratory insufficiency, atrial fibrillation, hydrothorax, renal failure, uroinfection

abdominal wall disruption: 2

Drainage of intra-abdominal abscess: 2

Completion pancreatectomy: 1

Stenosis of hepaticojejunostomy: 1

Bleeding from the pancreatic resectional surface: 1

Due to nonsurgical reason according to the visual estimation and/or subsequent determination of drain amylase level. In group 2, two reoperations were needed to perform due to an unsuccessful radiologic drainage of intra-abdominal abscess.

\section{Discussion}

Though pancreatic resections are associated with operative mortality in less than $5 \%$ of the patients, the morbidity rate is still considerable even in high-volume centers. The greatest problem for the surgeons is still the development of CR-POPF and its consequences, like abscess, hemorrhage, sepsis, multiorgan failure and even death. The huge number of technical innovations and recommendations indicate that pancreatic surgeons have aimed to minimize this problem; however, there has been no general agreement about the ideal method for the prevention [2]. The present work shows the efforts of a single institute. Operative mortality and morbidity rate were $0.7 \%$ and $43.8 \%$, respectively. These numbers are similar to the data of other high-volume centers. However, reoperation rate $(5.3 \%)$ would be lower, if the ultrasound-guided percutaneous drainage of intra-abdominal abscess would have been more successful. Due to the low rate of DGE, the antecolic duodeno-, or gastrojejunostomy with an additional Braun enteroenterostomy was our preferred reconstruction method, similar to others [11]. CR-POPF developed in less than $7 \%$ of the patients after Whipple procedure and this number seems to be advantageous, regarding the corresponding data of the literature and also the comparison to the results of our former series with an end-to-side single-layer pancreatojejunostomy. In the latter case the pre- and intraoperative data of 168 patients (age, gender, type of the disease, texture of the pancreas, type of operation) were identical with the present ones. The operative mortality rate was $3.8 \%$ (contrary $0.7 \%$ in the present series). However, we were not satisfied with the rate of CR-POPF in case of soft pancreas (19\%), so our technique was changed to the purse-string suture pancreatojejunostomy, which was associated with a $10.6 \%$ fistula rate. The advantage of the latter method may be due to the purse-string suture, when the stitch holes are inside of the bowel lumen. In case of an outside location of the stitch hole, the needle can hurt small pancreatic ducts, generating leakage of pancreatic juice [6]. So the purse-string type suture might be theoretically the key element of the effectiveness of the method. Since its first publication by Spivack and Wile [5], this principle was adopted in several modifications of the technique, for example the report of Nordback, Peng, Bartsch, Hashimoto, Kostov, and Hsu [6, 12-16]. It is important to emphasize that none of these authors applied additional sutures, which resulted in a pancreatic stitch hole outside the bowel lumen. The present series of more than 100 cases shows that the technique is very simple (only three stitches), safe, spares time and also suture material. Kostov and co-workers published the most simple method, namely they used only one purse-string stitch during pancreatogastrostomy, however without any fixing suture.
Table 3 Surgical complications $n: 31$, rate: $23.8 \%$

\begin{tabular}{llr}
\hline Rate of CR-POPF (B/C) & $6.9 \%$ \\
$n: 9(6 / 3)$ & In case of soft pancreas (7 out of 66) & $10.6 \%$ \\
& In case of fibrotic pancreas (2 out of 64) & $3.1 \%$ \\
DGE $n: 5$ & $4 \%$ (grade A) \\
Biliary fistula $n: 0$ & $0 \%$ \\
Postoperative bleeding $n: 1$ & $0.76 \%$ \\
Abdominal wall disruption $n: 2$ & $1.52 \%$ \\
Stenosis of hepaticojejunostomy $n: 1$ & $0.76 \%$ \\
Wound healing disorder $n: 14$ & $10.7 \%$ \\
\hline
\end{tabular}


Table 4 Groups defined by the mean level of drain amylase on the first postoperative day

$\begin{array}{ll}\text { Group } 1 & \text { No fistula }(n: 75) \\ \text { Group } 2 & \text { CR-POPF }(n: 9)\end{array}$

2137 U/1 (range: 6-46,000), 9 samples above $5000 \mathrm{U} / 1$

19,550 U/1 (range: 28-63,690)

1 sample under $5000 \mathrm{U} / 1$
Recently, there has been a great debate about the use of drainage, either omitting it, or selective drainage, or early removal $[8,17,18]$. Our drain removal policy was basically guided by the $5000 \mathrm{U} / 1$ cut-off level of drain amylase [8]; however, the time of drain removal was determined lastly by the current level. According to the absence or presence of CRPOPF, two categories could be distinguished. In group 1, the drain amylase level on the first postoperative day was $2137 \mathrm{U} /$ 1 in average, so the drain was removed on the mean fourth day postoperatively (at that time, the drain amylase level was $264 \mathrm{U} / 1$ in average) and CR-POPF did not develop. However, in group 2 (CR-POPF), the mean amylase level was found to be much higher, 19,550 U/1 on the first postoperative day. In these latter instances, the quality of drain effluent was also visually suspicious for fistula and the drain was left in situ. Thus, the drain amylase level on the first day raises the likelihood of fistula development, except nine cases in group 1, and one case in group 2, where the level was above or under the $5000 \mathrm{U} / 1$ limit, respectively. In the nine exceptions of group 1, the high amylase level significantly decreased on the subsequent days (no fistula), and in the one exception of group 2, the low amylase level considerably increased later (fistula). It means that drain amylase level on the first postoperative day together with its change and tendency are the dominant factor, whether CR-POPF would develop or not. So before drain removal, it is useful to repeat the measurement. This policy is similar to a recommendation, namely in patients with less than $5000 \mathrm{U} / 1$ drain amylase level on the first postoperative day and less than $350 \mathrm{U} / 1$ on the third day could be a practical guide for safe early drain removal [19]. Summarizing the drain management, we think that one soft silicon drain (only close to, but not in contact with the anastomosis) for 3-4 days is not able to cause a major problem. However, it gives the opportunity to check the drain amylase level on the first and subsequent postoperative days. As an indicator, it helps us to decide the time of drain removal as early as possible. Without drainage, there is an uncertainty, whether the radiologist will be able to put a drain into a peripancreatic fluid collection in necessity. In case of failure, a reoperation has to be carried out, as in two of our cases. A recently published argument against drainage is that intraabdominal drains can be dislocated during the postoperative period [20]. We routinely applied two measures to prevent the dislocation, namely the drain was placed after repositioning of the operating table and the pancreatojejunal anastomosis was covered with omentum. Proper position of the drain was detected on CT picture, selectively made in the early postoperative period.

Recently, the so-called "TRIANGLE operation" has been advocated to reach the maximal clearance of tissues between the mesenteric vessels and coeliac trunk during pancreatic cancer surgery [21]. Our first experiences are advantageous also with this technique. As in oncologic surgery generally, radicality and safety of the procedures have paramount importance in pancreatic surgery, too $[22,23]$.

\section{Conclusion}

Summing up, pancreatic surgeons must refine their own technique to decrease the complication rate as much as possible. The present single institute experience also reflects this ambition, namely the modification of the pancreatic anastomosis technique resulted in a simple and safe method.

Authors' contributions S. Ferencz: study concept and design, acquisition of data, analysis and interpretation of data, drafting of manuscript, critical review of manuscript. Zs. Bíró: acquisition of data, drafting of manuscript. A. Vereczkei: drafting of manuscript, critical review of manuscript. D. Kelemen: study concept and design, acquisition of data, analysis and interpretation of data, drafting of manuscript, critical review of manuscript.

Funding Information Open access funding provided by University of Pécs.

\section{Compliance with ethical standards}

Conflict of interest The authors declare that they have no conflict of interest.

Ethical approval All procedures performed in studies involving human participants were in accordance with the ethical standards of the institutional research committee and with the 1964 Helsinki declaration and its later amendments or comparable ethical standards.

This article does not contain any studies with animals performed by any of the authors.

Open Access This article is licensed under a Creative Commons Attribution 4.0 International License, which permits use, sharing, adaptation, distribution and reproduction in any medium or format, as long as you give appropriate credit to the original author(s) and the source, provide a link to the Creative Commons licence, and indicate if changes were made. The images or other third party material in this article are included in the article's Creative Commons licence, unless indicated otherwise in a credit line to the material. If material is not included in the article's Creative Commons licence and your intended use is not permitted by 
statutory regulation or exceeds the permitted use, you will need to obtain permission directly from the copyright holder. To view a copy of this licence, visit http://creativecommons.org/licenses/by/4.0/.

\section{References}

1. Assifi MM, Lindenmeyer J, Leiby BE, Grunwald Z, Rosato EL, Kennedy EP, Yeo CJ, Berger AC (2012) Surgical Apgar score predicts perioperative morbidity in patients undergoing pancreaticoduodenectomy at a high-volume center. J Gastroinest Surg 16:275-281

2. Shrikhande SV, Sivasanker M, Vollmer CM, Friess H, Besselink MG, Fingerhut A, Yeo CJ, Fernandez-delCastillo C, Dervenis C, Halloran C, Gouma DJ, Radenkovic D, Asbun HJ, Neoptolemos JP, Izbicki JR, Lillemoe KD, Conlon KC, Fernandez-Cruz L, Montorsi M, Bockhorn M, Adham M, Charnley R, Carter R, Hackert T, Hartwig W, Miao Y, Sarr M, Bassi C, Büchler MW, International Study Group of Pancreatic Surgery (ISGPS) (2017) Pancreatic anastomosis after pancreatoduodenectomy: a position statement by the International Study Group of Pancreatic Surgery (ISGPS). Surgery 161:1221-1234

3. Kelemen D, Papp R, Vereczkei A (2013) Pancreatojejunostomy with purse-string suture. Magy Seb 66:348-352

4. Kelemen D, Papp R, Kaszás B, Bíró Z, Vereczkei A (2016) Pancreatojejunostomy with modified purse-string suture technique. Langenbeck's Arch Surg 401:403-407

5. Spivack B, Wile AG (1994) Purse-string modification of the dunking pancreatojejunostomy. Br J Surg 81:431-432

6. Peng SY, Wang JW, Hong PF, Liu YB, Wang YF (2011) Binding pancreaticoenteric anastomosis: from binding pancreaticojejunostomy to binding pancreaticogastrostomy. Updat Surg 63:69-74

7. Roulin D, Demartines N (2020) Evidence for enhanced recovery in pancreatic surgery. Langenbeck's Arch Surg Published online: 01 July 2020. https://doi.org/10.1007/s00423-020-01921-z

8. Bassi C, Molinari E, Malleo G, Crippa S, Butturini G, Salvia R, Talamini G, Pederzoli P (2010) Early versus late drain removal after standard pancreatic resections: results of a prospective randomized trial. Ann Surg 252:207-214

9. Bassi C, Marchegiani G, Dervenis C, Sarr M, Abu Hilal M, Adham M, Allen P, Andersson R, Asbun HJ, Besselink MG, Conlon K, del Chiaro M, Falconi M, Fernandez-Cruz L, Fernandez-del Castillo C, Fingerhut A, Friess H, Gouma DJ, Hackert T, Izbicki J, Lillemoe KD, Neoptolemos JP, Olah A, Schulick R, Shrikhande SV, Takada T, Takaori K, Traverso W, Vollmer CR, Wolfgang CL, Yeo CJ, Salvia R, Buchler M, International Study Group on Pancreatic Surgery (ISGPS) (2017) The 2016 update of the International Study Group (ISGPS) definition and grading of postoperative pancreatic fistula: 11 years after. Surgery 161:584-591

10. Wente MN, Bassi C, Dervenis C, Fingerfut A, Gouma DJ et al (2007) Delayed gastric emptying (DGE) after pancreatic surgery: a suggested definition by the International Study Group of Pancreatic Surgery (ISGPS). Surgery 142:761-768
11. Schorn S, Demir IE, Vogel T, Schirren R, Reim D, Wilhelm D, Friess H, Ceyhan GO (2019) Mortality and postoperative complications after different types of surgical reconstruction following pancreaticoduodenectomy - a systematic review with meta-analysis. Langenbeck's Arch Surg 404:141-157

12. Nordback I, Lamsa T, Laukkarinen J, Leppiniemi J, Kellomaki M (2008) Pancreatico-jejunostomy with a biodegradable pancreatic stent and without stitches through the pancreas. HepatoGastroenterology 55:319-322

13. Bartsch DK, Langer P, Kanngiesser V, Fendrich V, Dietzel K (2012) A simple and safe anastomosis for pancreatogastrostomy using one binding purse-string and two transfixing mattress sutures. Int J Surg Oncol 2012:1-7. https://doi.org/10.1155/2012/718637

14. Hashimoto D, Hirota M, Yagi Y, Baba H (2013) End-to-side pancreatico-jejunostomy without stitches in the pancreatic stump. Surg Today 43:821-824

15. Kostov D, Kobakov G, Yankov D (2015) Pancreaticogastrostomy with one continuous seromuscular circular suture. Surg Chron 20: 251-254

16. Hsu CW, Lin LF, Law MK (2016) Purse-string suture without pancreatic parenchymal stitches in pancreaticojejunostomy during laparoscopic pancreaticoduodenectomy. Surg Pract 20:87-91

17. Witzigmann H, Diener MK, Klenkötter S, Rossion I, Bruckner T et al (2016) No need for routine drainage after pancreatic head resection: the dual-center, randomized controlled PANDRA trial. Ann Surg 264:528-537

18. Nitsche U, Müller TC, Späth C, Cresswell L, Wilhelm D, Friess H, Michalski CW, Kleeff J (2014) The evidence based dilemma of intraperitoneal drainage for pancreatic resection - a systematic review and meta-analysis. BMC Surg 14:76-88

19. Villafane-Ferriol N, Van Buren IIG, Mendez-Reyes JE, McElhany AL, Massarweh NN et al (2018) Sequential drain amylase to guide drain removal following pancreatectomy. HPB 20:514-520

20. Marchegiani G, Ramera M, Viviani E, Lombardo F, Cybulski A, Chincarini M, Malleo G, Bassi C, Zamboni GA, Salvia R (2019) Dislocation of intra-abdominal drains after pancreatic surgery: results of a prospective observational study. Langenbeck's Arch Surg 404:213-222

21. Schneider M, Strobel O, Hackert T, Büchler MW (2019) Pancreatic resection for cancer - the Heidelberg technique. Langenbeck's Arch Surg 404:1017-1022

22. Sahakyan MA, Kleive D, Kazaryan AM, Aghayan DL, Ignjatovic D, Labori KJ, Røsok BI, Edwin B (2018) Extended laparoscopic distal pancreatectomy for adenocarcinoma in the body and tail of the pancreas: a single-center experience. Langenbeck's Arch Surg 403:941-948

23. Sivasanker M, Desouza A, Bhandare M, Chaudhari V, Goel M, Shrikhande SV (2019) Radical antegrade modular pancreatosplenectomy for all pancreatic body and tail tumors: rationale and results. Langenbeck's Arch Surg 404:183-190

Publisher's note Springer Nature remains neutral with regard to jurisdictional claims in published maps and institutional affiliations. 